
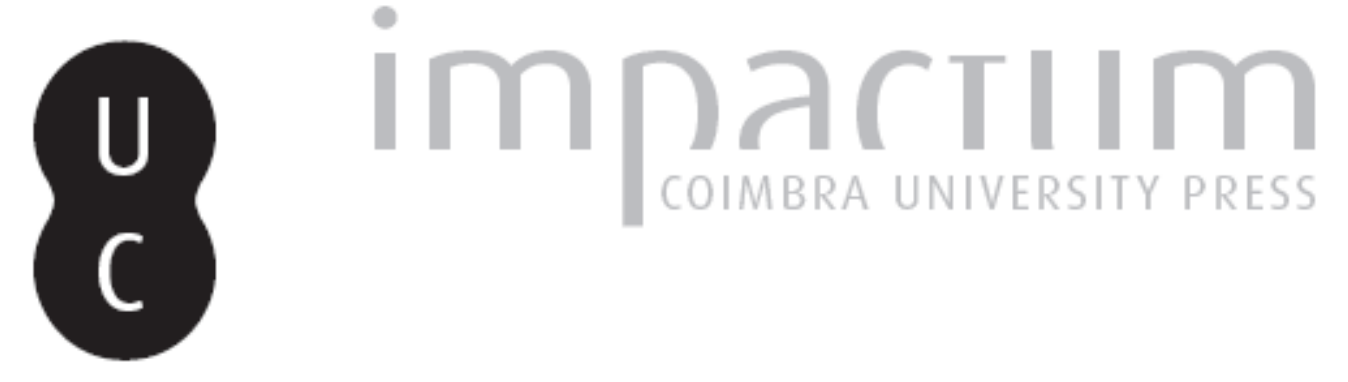

\title{
Doutoramento em Geografia Física na área da Climatologia Urbana
}

Autor(es): $\quad$ Rebelo, Fernando

Publicado por: Associação Portuguesa de Riscos, Prevenção e Segurança

URL persistente:

URI:http://hdl.handle.net/10316.2/40124

DOI:

DOI:https://doi.org/10.14195/1647-7723_6_7

Accessed : $\quad$ 26-Apr-2023 12:12:06

A navegação consulta e descarregamento dos títulos inseridos nas Bibliotecas Digitais UC Digitalis, UC Pombalina e UC Impactum, pressupõem a aceitação plena e sem reservas dos Termos e Condições de Uso destas Bibliotecas Digitais, disponíveis em https://digitalis.uc.pt/pt-pt/termos.

Conforme exposto nos referidos Termos e Condições de Uso, o descarregamento de títulos de acesso restrito requer uma licença válida de autorização devendo o utilizador aceder ao(s) documento(s) a partir de um endereço de IP da instituição detentora da supramencionada licença.

Ao utilizador é apenas permitido o descarregamento para uso pessoal, pelo que o emprego do(s) título(s) descarregado(s) para outro fim, designadamente comercial, carece de autorização do respetivo autor ou editor da obra.

Na medida em que todas as obras da UC Digitalis se encontram protegidas pelo Código do Direito de Autor e Direitos Conexos e demais legislação aplicável, toda a cópia, parcial ou total, deste documento, nos casos em que é legalmente admitida, deverá conter ou fazer-se acompanhar por este aviso.

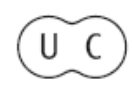




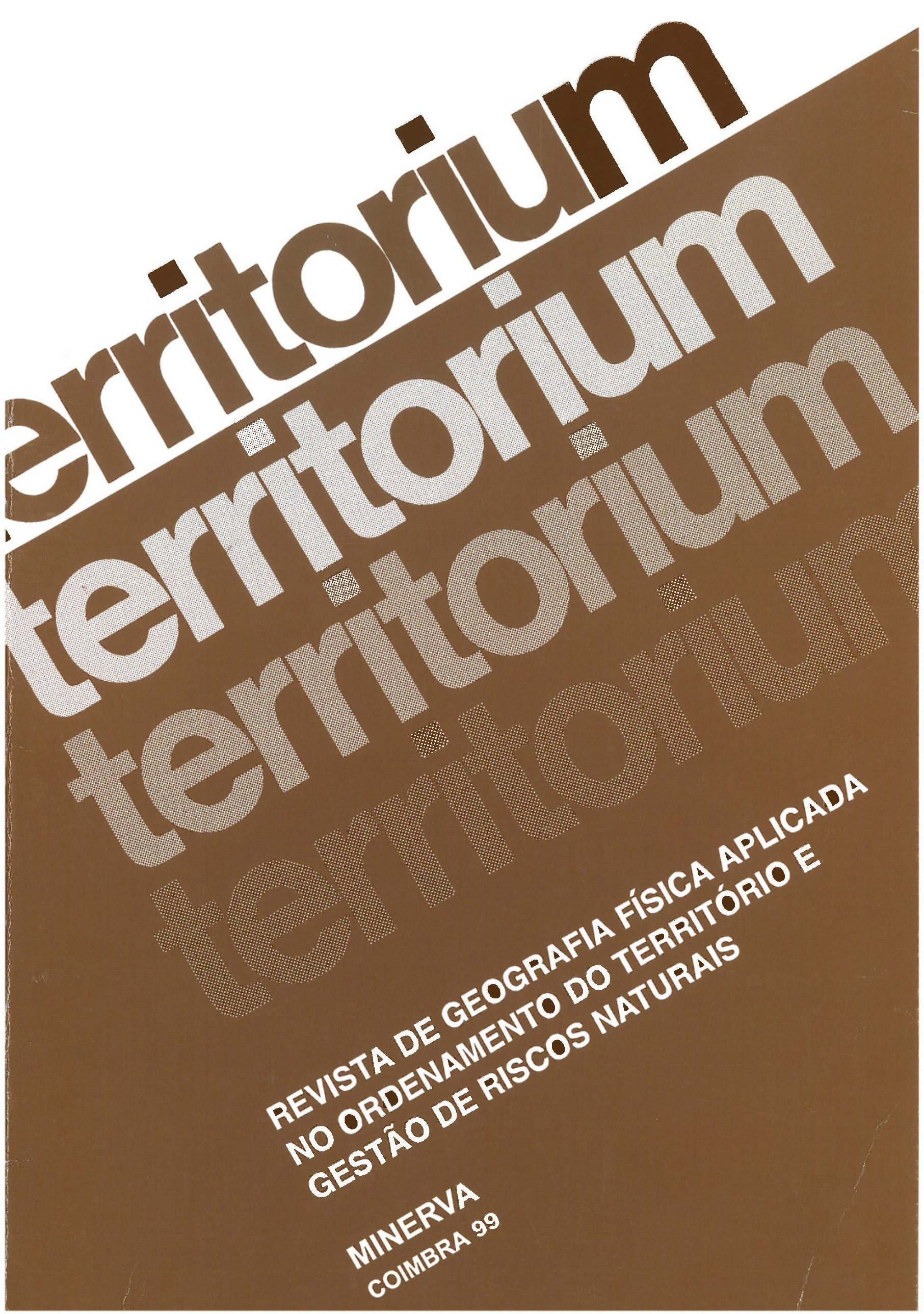


FERREIRA, Carmen Gonçalves (1997) - "O eucalipto e a cindínica ecológica. "Culpado" ou "inocente"? Territorium, 4. p. 133-141.

GANHO, Nuno (1996) - "Espaços verdes no interior do tecido urbano de Coimbra, Portugal. Contrastes topoclimáticos, influência bioclimática e riscos de poluição atmosférica". Territorium, 3, p. 35-56.

GANHO, Nuno (1998) - O Clima Urbano de Coimbra. Estudo de Climatologia local aplicada ao ordenamento urbano. Tese de Doutoramento em Geografia Física apresentada à Faculdade de Letras da Universidade de Coimbra.

LOURENÇO, Luciano (1989) - O Rio Alva. Hidrogeologia, Geomorfologia, Climatologia, Hidrologia. Coimbra, Instituto de Estudos Geográficos.

LOURENÇO, Luciano (1991) - "Uma fórmula expedita para determinar o índice meteorológico de risco de eclosão de fogos florestais em Portugal Continental". Cademos Cientificos sobre Incêndios Florestais, 2, p. 3-63.

LOURENÇO, Luciano (1994) - "Risco de incêndio florestal em Portugal continental". Informação Florestal, 4, p. 22-32.

LOURENÇO, Luciano (1995) - "Prosepe - Projecto de Sensibilização da população escolar. Actividades desenvolvidas e em curso". Territorium, 2, p. 70-72.

LOURENÇO, Luciano (1996) - Serras de Xisto do Centro de Portugal. Contribuição para o seu conhecimento geomorfológico e geoecologico. Tese de Doutoramento em Geografia Física apresentada à Faculdade de Letras da Universidade de Coimbra.

MARTONNE, Emmanuel de (1953) - Traité de Geographie Physique, trad. port., Panorama da Geografia, vol. I, Lisboa, Edições Cosmos.

MONTEIRO, Ana (1993)-O Clima Urbano do Porto. Contribuição para a definição das estratégias de planeamento e ordenamento do território. Tese de Doutoramento em Geografia Física apresentada à Faculdade de Letras da Universidade do Porto.

PEDROSA, António de Sousa (1993) - Serra do Marão. Estudo de Geomorfologia. Tese de Doutoramento em geografia Física apresentada à Faculdade de Letras da Universidade do Porto.

PEDROSA, António de Sousa (1994) - "As actividades humanas e os processos morfogenéticos. O exemplo da Serra do Marão". Territorium, 1, p. 23-34.
PEDROSA, António de Sousa e MARQUES, Bernardo de Serpa (1994) - "Man's action and slope erosion. A case study in Tâmega Basin". Territorium, 1, p. 35-41.

PEDROSA, António de Sousa, BATEIRA, Carlos e SOARES, Laura (1995) - "Covelo do Gerês. Contributo para o estudo dos movimentos de massa no norte de Portugal". Territorium, 2, p. 21-32.

RAMOS, Maria Catarina de Melo (1994) - Condições Geomorfológicas e Climáticas das Cheias da Ribeira de Tera e do Rio Maior (Gacia Hidrográfica do Tejo). Tese de Doutoramento apresentada à Faculdade de Letras da Universidade de Lisboa.

RAPOSO, António Guilherme B. (1998) - "Breve nota sobre a tragédia da Ribeira Quente (S. Miguel, Açores) ocorrida na madrugada de 31 de Outubro de 1997)". Territorium, 5, p.73-74.

REBELO, Fernando (1977) - "A acção humana como causa de desabamentos e deslizamentos - análise de um caso concreto". Biblos, 57, p. 629-644.

REBELO, Fernando (1981) - "Condições de tempo favoráveis à ocorrência de incêndios florestais. Análise dos dados referentes a Julho e Agosto de 1975 na área de Coimbra". Biblos, 56, p. 653-673.

REBELO, Fernando (1997) - "Risco e crise nas inundações rápidas em espaço urbano. Alguns exemplos portugueses analisados a diferentes escalas". Territorium, 4, p. 29-47.

REBELO, Fernando e GANHO, Nuno (1998) - "As inundações do Outono de 1997 no Sul de Portugal". Territorium, 5, p. 25-30.

ROXO, Maria José (1994) - A Acção Antrópica no Processo de Degradação de Solos. A Serra de Serpa e Mértola. Tese de Doutoramento em Geografia Física apresentada à Faculdade de Ciências Humanas e Sociais da Universidade Nova de Lisboa.

SANTOS, José Gomes (1997) - "Instabilidade de vertentes e riscos de movimentos de terreno. 0 exemplo da área Vila Seca-Lamas (a Sul de Coimbra)". Territorium, 4, p. 79-98.

ZÊZERE, JoséLuís (1997) - Movimentos de Vertente e Perigosidade Geomorfológica na Região a Norte de Lisboa. Tese de Doutoramento em Geografia Física apresentada à Faculdade de Letras da Universidade de Lisboa.

\section{Doutoramento em Geografia Física na área da Climatologia Urbana}

\section{Fernando Rebelo}

o Clima Urbano de Coimbra. Estudo de Climatologia local aplicada ao ordenamento urbano foi o título escolhido por Nuno Ganho para a tese de doutoramento em Geografia Física, que defendeu publicamente em Coimbra no dia 29 de Outubro de 1998.
Na sua forma actual, trata-se dum livro de 551 páginas, das quais as últimas 50 correspondem a uma importante Bibliografia e aos índices de quadros e figuras que ilustram o texto.

Depois da "Introdução", que funciona como primeiro capítulo, vem um segundo capítulo intitulado 
"O regime climático de Coimbra" no qual se analisam os dados do Instituto Geofísico da Universidade (IGU). Seguem-se mais cinco capítulos: "A base de análise do clima local: a amostra e os tipos de tempo", "Contrastes termohigrométricos espaciais", "Padrões termohigrométricos espaciais", "Contrastes locais" e "Conclusão e aplicações ao ordenamento urbano".

Para alguns leitores desta tese, o que mais se salientará será o trabalho de recolha e tratamento de dados já publicados ou inéditos que ela exigiu. Para outros, será talvez a pesquisa de campo que levou Nuno Ganho a percorrer, durante dezenas de dias, ruas, praças e jardins de Coimbra, às mais variadas horas do dia ou da noite, nas mais diversas condições de tempo. Para outros, ainda, será a maneira como, por vezes, surge a preocupação de aplicar ao ordenamento urbano todo o trabalho realizado.

Esta tese mostra tudo isso. E mostra-o num livro profusamente ilustrado com gráficos e cartogramas, muito bem escrito, num português fluente e agradável que atenua as dificuldades que por vezes se possam levantar com a linguagem técnico-científica. Com essa obra, é indubitável que o clima da cidade passa a ficar muito melhor conhecido, algumas ideias feitas são desmitificadas e, acima de tudo, passa a existir um documento imprescindível para o ordenamento urbano em Coimbra.

\section{IV e V Encontros de Coimbra sobre Riscos Naturais}

\section{Fernando Rebelo}

Depois dos primeiros quatro Encontros sobre Riscos Naturais Urbanos, efectuados em 1993, 1994, 1996 e 1997, realizou-se, no dia 30 de Outubro de 1998, no Auditório da Reitoria da Universidade o V Encontro sobre Riscos Naturais, agora, portanto, com uma designação mais simples e ao mesmo tempo mais abrangente.

$\mathrm{Na}$ verdade, o IV Encontro, realizado a 24 de Janeiro de 1997, já não foi exclusivamente sobre Riscos Naturais verificáveis em meios urbanos. Pessoalmente, falámos de "Inundações rápidas e movimentos de terras" e a Prof ${ }^{a}$ Maria Sala, da Universidade de Barcelona, apresentou uma comunicação intitulada "Riesgos de inundación rápida. Ejemplos de Catalunya y de la reciente catástrofe en el Pirineo (Biescas)". Estava dado o tom a um encontro de riscos que já não se limitava aos riscos naturais urbanos. Depois, Carmen Ferreira, Assistente da Universidade do Porto, falou de riscos colocados pelas plantações de eucaliptos e o Doutor António Dinis Ferreira, do Departamento de Ambiente e Ordenamento da Universidade de Aveiro tratou das consequências hidrológicase pedológicas das mudanças florestais. Os Prof.P. Proença da Cunha (Departamento de Ciências da Terra da Faculdade de Ciências e Tecnologia da Universidade de Coimbra - FCTUC) e A. Campar de Almeida (Institutode Estudos Geográficos da Faculdade de Letras da mesma Universidade - IEG/FLUC) referiram-se a riscos de inundação (e outros) relacionados com o mar na área da Figueira da Foz. A então recém licenciada em Geografia,
Maria Manuela Bento (Núcleo de Investigação Científica de Incêndios Florestais, FLUC) falou dos processos erosivos actuais na vertente norte da Serra da Gardunha, tal como J. Gomes dos Santos (IEG/FLUC) tratou dos riscos de movimentações de terrenos, com exemplos concretos nos arredores sul de Coimbra, afectando infraestruturas de circulação em meio rural. Finalmente, o Prof. Lúcio Cunha (IEG/FLUC) relacionou o ensino da Geografia com o estudo dos riscos naturais apresentando um mapa de riscos elaborado noâmbito de um trabalho académico recente. Uma parte destas comunicações foi publicada sob a forma de artigos na Territorium, números 4 e 5.

Tal como o IV Encontro, organização conjunta do Instituto de Estudos Geográficos e do Centro de Estudos Geográficos da Faculdade de Letras, o V Encontro teve também mais de 300 participantes, principalmente geógrafos, mas também geólogos, biólogos, engenheiros e arquitectos, alguns dos quais, docentes das Universidades de Coimbra, Porto, Lisboa, Aveiro e Minho.

Apresentámos a comunicação de abertura, dedicada ao tema "As inundações do Outono de 1997 no Sul de Portugal", que, sob a forma de artigo feito com a colaboração de Nuno Ganho, acabava de ser publicado na Territorium (número5). Seguiram-se comunicações dos Prof. Doutores Maria João Alcoforado, da Universidade de Lisboa, sobre a evolução climática nos séculos XVII e XVIII, e Felipe Fernandez, da Universidade Autónoma de Madrid, sobre a poluição atmosférica urbana nesta cidade; ambas as comuni- 